Journal of Engineering and Applied Sciences 15 (1): 165-170, 2020

ISSN: 1816-949X

(C) Medwell Journals, 2020

\title{
Mechanical Properties and Damage Analysis of Laminates with Hybrid Fiber Volume Fraction
}

\author{
Amany G.B. Micheal \\ Centre for Advanced Materials (CAM), The British University in Egypt (BUE), \\ El Sherouk, Cairo, Egypt
}

\begin{abstract}
This study is concerned with modelling the mechanical behavior and damage of glass fiber composite laminates that exhibit hybrid fiber volume fraction. The Transformation Field analysis (TFA) is implemented in formulation while the composite is modeled using Mori-Tanaka averaging model. The formulation is verified versus an experimental program conducted at the Center for Advanced Materials (CAM) in the British University in Egypt (BUE). The studied laminates are with different lay ups and subjected to uniaxial bending and tension. The investigated lay ups are $\left(0^{\circ}\right)$ glass fiber symmetric laminate with thickness $37.0 \mathrm{~mm}$ and consists of 48 plies and a $\left(0 / \pm 45^{\circ}\right)$ symmetric laminate comprised of 12 layers of $\left(0 / \pm 45^{\circ}\right)$ glass fiber textile resulting in 36 plies with total thickness $10.7 \mathrm{~mm}$. The fiber volume fraction (FVF) is $62 \%$ for both lay ups. The hybridization in fiber volume fraction is implemented by assigning low FVF of $40 \%$ for some core plies with variable depths. The core depths studied for the $\left(0^{\circ}\right)$ laminate are $t / 4, t / 2$ and $3 t / 4$ where $t$ is half the thickness of the laminate while the core depths for the $\left(0 / \pm 45^{\circ}\right)$ layup are $t / 3$ and $2 t / 3$. A comparison according to different criteria between the results of the above-mentioned lay ups and the results of the same laminate when all plies have the same volume fraction of $62 \%$ is conducted. The comparison criteria include longitudinal and flexural stiffness, the tensile strength and bending moment at the onset of failure together with ultimate bending moment the laminate can sustain. For bending case, the results show that for both the $\left(0^{\circ}\right)$ and $\left(0 / \pm 45^{\circ}\right)$ laminates, minor reduction in the mechanical properties in both the undamaged and damaged state takes place. The reduction ranges from $0-12 \%$ for all recorded variables. For the axial tension, the loss in mechanical properties is more rigorous. For the off-axis layup, laminate may lose $23 \%$ of its stiffness for large core depths. The effect is more pronounced for the load capacity where the laminate may lose up to $30 \%$ of its strength according to the depth of the low FVF core.
\end{abstract}

Key words: Laminate, fiber volume fraction, eignstress, failure, rigorous, loss

\section{INTRODUCTION}

The composite materials application in industry is now gaining more land. The mechanical properties of a composite depends on the constituent's properties and primarily on the Fiber Volume Fraction (FVF). The technology adopted in the manufacturing process of a composite plays a major role in obtaining a desired fiber volume fraction implemented in the design of a certain structure or part of it. Some researchers investigated the effect of fiber volume fraction on the mechanical properties of a composite. Among them is Salgar Swapnil et al. (2017) who conducted an experimental investigation on composite with different volume fractions. They studied the mechanical properties of composite with volume fractions 40,50 and $60 \%$. They concluded that the best behaviour is obtained with volume fraction 50\%. Sureshkumar et al. (2014) investigated a glass fiber/polyurethane composite with different volume fraction of 70,65 and $60 \%$. They stated that increasing the fiber volume fraction increases the tensile and flexural strength but for higher FVF the composite may suffer lower strength due to lack of adhesive, (Sureshkumar et al., 2014).

Numerical modelling of fibrous composite has taken much interest. The modelling ranges from a macro scale where the overall composite properties are employed in the analysis using some simple models such as rule of mixture. Models that are more precise are found in the literature such as Mori-Tanka (MT) averaging model (Mori and Tanaka, 1973). For which the composite is considered as a fiber inclusion in a matrix medium and the stresses in both fiber and matrix can be obtained from the composite stresses via. some concentration factors. Other micro-mechanical models are now on going where a certain Representative Volume Element (RVE) describes the behaviour of the composite when repeated in a certain pattern. As an example of the RVE Models, is the Periodic Hexagonal Array Model (PHA) (Bahei-El-Din and Botrous, 2003). The challenge in 
dealing with these models is to model damage. One of the most effective ways of modelling damage is the transformation field analysis (Dvorak and Benveniste, 1992). In such formulation, all the non-recoverable sources of stresses and strains such as thermal, electrical or damage, are treated as elastic eign values that affect the behavior of the composite through some influence functions.

This study is concerned with investigating the mechanical behaviour of composite laminates that possess hybrid fiber volume fraction. The investigation covers the undamaged stage and progressive damage phase. The MT averaging model is employed and to model damage the TFA is implemented. Section 2 is assigned to materials and methods. In this section the TFA formulation for composite that exhibits damage together with the implemented failure criteria are presented in conjunction with the MT Model. In subsection verification of the model, the model is verified against experimental results. The proceeding section is assigned to present the investigated laminates with regards to geometry, fiber volume fraction, layup, materials properties and loading conditions. Results and discussion are presented in sections 3 and 4 respectively. Conclusion of the results is presented in section 5 .

\section{MATERIALS AND METHODS}

Averaging model formulation: Let us consider a composite laminate with number of $N$ plies and thickness 2t. The laminate is subjected to normal force $\mathrm{N}$ and bending moment $\mathrm{M}$ as shown in Fig. 1. The individual ply stress can be expressed as function of the laminate properties and loads as follows:

$$
\hat{\sigma}_{i}\left(z_{i}\right)=P_{i} N+Q_{i} M+\sum_{j=1, n} U_{i j} \hat{\lambda}_{j}
$$

The coefficient matrices $\mathrm{P}_{\mathrm{i}}$ and $\mathrm{Q}_{\mathrm{i}}$ denote stress distribution factors of ply $\mathrm{i}$ that depend on the ply properties and the ply distance from the mid plane. Uij denotes stress transformation influence functions that takes into account the effect of any source of non-recoverable stresses $\hat{\lambda}_{\mathrm{j}}$ that occur in any other ply j on the stress state of ply i. These non-recoverable stresses may be due to thermal, plastic or, as in the case of this work, damage. All matrices are function of elastic moduli, fiber volume fraction of the laminas and the laminate layup. A closed form of these matrices can be found in Micheal and Bahei-El-Din (2017).

In averaging models, any ply i comprises of two phases, fiber and matrix. The phase stresses are linked to the ply stresses through a certain stress concentration factor in addition to the effect of any non-recoverable source of stress that takes place in the other phase. Implementing the Transformation Field Analysis (TFA)

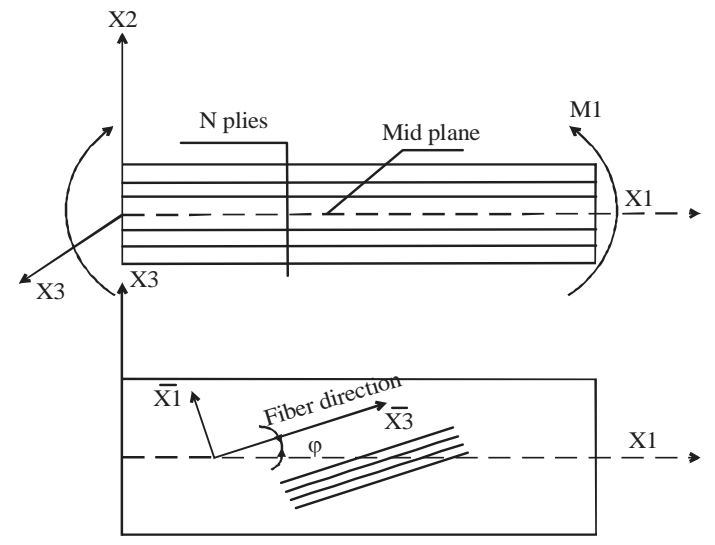

Fig. 1: Geometry and load of a fibrous laminate

in the formulation the phase stresses and strains can be written as follows (Bahei-El-Din and Botrous, 2003):

$$
\begin{aligned}
& \sigma_{\mathrm{r}}=\mathrm{B}_{\mathrm{r}} \bar{\sigma}+\sum_{\mathrm{s}=\mathrm{f}, \mathrm{m}} \mathrm{F}_{\mathrm{rs}} \lambda_{\mathrm{s}} \mathrm{r}=\mathrm{f}, \mathrm{m} \\
& \varepsilon_{\mathrm{r}}=\mathrm{A}_{\mathrm{r}} \bar{\varepsilon}+\sum_{\mathrm{s}=1, \mathrm{Q}} \mathrm{D}_{\mathrm{rs}} \mu_{\mathrm{s}} \mathrm{r}=\mathrm{f}, \mathrm{m}
\end{aligned}
$$

In analogy to the ply stress, the phase stress and strain $\sigma_{\mathrm{r}}$ and $\varepsilon_{\mathrm{r}}$ depend on the ply stress $\bar{\sigma}$ and strain $\bar{\varepsilon}$ where the upper dash denoted the fields in the local coordinate system $\bar{X}$ in addition to the eignstress $\lambda_{\mathrm{s}}$ and eignstrain $\mu_{\mathrm{s}}$ encountered in the phases.

$B_{r}$ and $A_{r}$ are the stress and strain concentration factors while $F_{r s}$ and $D_{r s}$ are the stress and strain influence functions. They too are function of the elastic properties of the phases and can be found in closed form for Mori and Tanaka (1973) averaging model of composites. Their expressions are given in Bahei-El-Din and Botrous (2003).

The strain $\varepsilon_{0}$ and curvature $\kappa$ of the mid plane of the laminate can be expressed as follow:

$$
\begin{gathered}
\varepsilon_{0}=A^{\prime} N+B^{\prime}+f^{\prime} \\
\kappa=C^{\prime} N+D^{\prime} M+g^{\prime},
\end{gathered}
$$

The first two terms in Eq. 4 and 5 represent the strain and curvature due to the mechanical loads. The third term represents the effects caused by the laminas eignstresses $\lambda_{\mathrm{i}}$ :

$$
\mathrm{f}^{\prime}=\sum_{\mathrm{i}=1, \mathrm{n}} \mathrm{t}_{\mathrm{i}} \lambda_{\mathrm{i}}, \mathrm{g}^{\prime}=\sum_{\mathrm{i}=1, \mathrm{n}}\left(\mathrm{t}_{\mathrm{i}} \mathrm{z}_{\mathrm{i}}\right) \lambda_{\mathrm{i}}
$$

The lamina eignstress is function of the phases' counterparts of eigenvalues $\lambda_{\mathrm{r}}$ as follows: 


$$
\bar{\lambda}_{\mathrm{i}}=\sum_{\mathrm{r}=1, \mathrm{Q}} \mathrm{V}_{\mathrm{r}} \mathrm{A}_{\mathrm{r}}^{\mathrm{T}} \lambda_{\mathrm{r}}^{(\mathrm{i})}
$$

Again, the upper dash relates the eign fields in the local coordinates of the ply. This should be transformed to the global coordinate system before applying into Eq. 6.

Failure criteria and modelling: To detect damage in averaging model, the average phase normal stresses in lamina local axis found in Eq. 2, should be checked against the ultimate material strength for $\sigma_{\mathrm{uT}}^{(\mathrm{r})}$ tension or compression $\sigma_{\mathrm{uc}}^{(\mathrm{r})}$. These failure criteria for normal stresses can be written as (Micheal and Bahei-El-Din, 2017):

$$
\bar{\sigma}_{i i}^{(\mathrm{r})}=\sigma_{\mathrm{uT}}^{(\mathrm{r})} \text { if } \bar{\sigma}_{i i}^{(\mathrm{r})}>0, \bar{\sigma}_{i i}^{(\mathrm{r})}=\sigma_{\mathrm{uc}}^{(\mathrm{r})} \text { if } \bar{\sigma}_{i i}^{(\mathrm{r})}<0, \mathrm{r}=\mathrm{f}, \mathrm{m}, \mathrm{i}=1,3
$$

If this failure criterion is satisfied, stresses in failed directions should vanish. Matrix shear may attain an ultimate value $\tau_{\mathrm{u}}{ }^{\mathrm{m}}$ which causes matrix to slip transversely or longitudinally with respect to fibers. Taking into account the existence of friction between fiber and matrix due to surface asperities, these failure criteria can be written as follows:

$$
\begin{gathered}
\frac{1}{2}\left|\bar{\sigma}_{11}^{\mathrm{m}}-\bar{\sigma}_{22}^{\mathrm{m}}\right|+\frac{1}{2} \eta_{\mathrm{T}}\left\langle\bar{\sigma}_{11}^{\mathrm{m}}+\bar{\sigma}_{22}^{\mathrm{m}}\right\rangle=\tau_{\mathrm{u}}^{\mathrm{m}} \\
\bar{\sigma}_{13}^{\mathrm{m}}+\eta_{\mathrm{L}}\left\langle\bar{\sigma}_{22}^{\mathrm{m}}\right\rangle=\tau_{\mathrm{u}}^{\mathrm{m}}
\end{gathered}
$$

where, $\eta_{T}$ and $\eta_{\mathrm{L}}$ are coefficients of friction for matrix slip in the transverse and longitudinal direction, respectively and $(x)=x$ if $x<0,(x)=0$ if $x \geq 0$. If failure criteria Eq. 9 is satisfied both $\bar{\sigma}_{11}^{\mathrm{m}}$ and $\bar{\sigma}_{22}^{\mathrm{m}}$ should set to zero and satisfying Eq. 10 requires $\bar{\sigma}_{13}^{\mathrm{m}}$ to vanish.

If damage takes place, there should be additional eignstresses, which are the unknowns that should be added to the system to fulfill the condition of vanishing stresses. Isolating the stress components that should vanish after damage in a reduced version of Eq. 2 and giving them a value of zero,the equation can be solved for the unknown eignstresses.

The eignstresses can then be applied back in the full version of Eq. 2 and the phase stresses due to damage is super-positioned with non-damage stresses. The procedure should be repeated until full saturation of failure at a certain load level is attained. Applying back the resulting eignstresses in Eq. 7, 6, 4 and 5, the laminate mid plane strain and curvature are obtained.
Verification of the model: To verify the previously mention model for composite laminate damage, a bench mark problem is solved and compared with experimental results. The experimental program is conducted on a composite laminate of 4 layers of glass fiber textile $\left(0 / \pm 45^{\circ}\right)$ ETXL1200-SBIL with thickness $2.5 \mathrm{~mm}$, width $25 \mathrm{~mm}$ and length $250 \mathrm{~mm}$ with a symmetric layup ( $+45 /-$ 45/0/+45/-45/0/0/-45/+45/0/-45/+45) and manufactured using vacuum infusion. The Fiber Volume Fraction (FVF) of the specimen is 0.56 and the matrix is Araldite LY 1567. Six specimens are tested and the average results are implemented in the comparison. The specimens are manufactured at the Centre for Advanced Materials (CAM) in the British University in Egypt (BUE) and tested under tension using a Universal Testing Machine with loading rate $2 \mathrm{~mm} \mathrm{~min}^{-1}$ according to ASTM standard with the designation D3039/D3039M-00 (ASTM, 2017). The experimental program results can be found in the work published by Bahei El-Din YA 2011. The same problem is solved using the TFA averaging model presented in the previous section. The material properties implemented in the analysis are as given in Table 1.

The comparison of the results are given in Fig. 2. The compatibility of the undamaged part of the two curves is clear. The onset of failure in the model takes place at stress $460 \mathrm{MPa}$ in the off axis plies due to matrix tensile failure according to the failure criteria depicted in Eq. 8-10 while the experiment shows earlier on set of failure. However, for the TFA Model, failure results in large increase in strains at onset of failure then for subsequent behavior both the analytical and experimental results show good agreement.

\begin{tabular}{|c|c|c|c|c|c|c|c|}
\hline Materials & $\mathrm{E}(\mathrm{GPa})$ & $v$ & $\sigma_{\mathrm{ut}}(\mathrm{MPa})$ & $\sigma_{\mu r}(\mathrm{MPa})$ & $\tau_{\|}(\mathrm{MPa})$ & $\eta_{I}$ & $\eta_{T}$ \\
\hline Araldite LY 1564 epoxy & 3.35 & 0.35 & 72 & 115 & 60 & 0.268 & 0.268 \\
\hline Glass fiber & 73.00 & 0.21 & 1900 & ---- & ---- & ---- & ---- \\
\hline
\end{tabular}

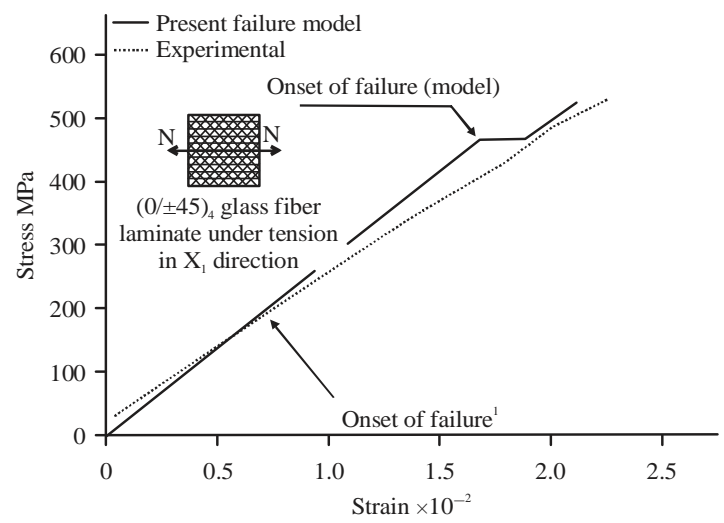

Fig. 2: Verification of damage model (ASTM, 2017)

Table 1: Material properties 
Glass fiber composite laminates with hybrid volume fraction: The model presented in the previous sections is implemented in the analysis of a composite laminates with hybrid fiber volume fraction and compared with the results of conventional ones. Two values of fiber volume fraction are studied 62 and $40 \%$. From the practical point of view, low values of the FVF can be found when a composite is manufactured using hand layup while the higher values are obtained for manufacturing using vacuum infusion or prepreg techniques (Bahei El-Din, 2011).

The first layup to be studied is a laminate with total thickness of $36 \mathrm{~mm}$ and comprised of 48 layers of $\left(0^{\circ}\right)$ plies of glass fiber/epoxy matrix with the properties presented in Table 1 . The single ply thickness is $0.75 \mathrm{~mm}$ and the laminate is subjected to bending moment in $\mathrm{X}_{1}$ direction as given in Fig. 1.

For comparison, firstly, a problem is solved when the volume fraction of all plies is maintained at $62 \%$ whose designation is Type I. Then, the same laminate is analysed under same loading and assigning a lower value of FVF of $40 \%$ for core plies with thickness $t / 4, t / 2$ and $3 t / 4$ where $t$ is the laminate half thickness as shown in Fig. 3-5. This core thickness can be attained by assigning the lower FVF value for 12, 24, 36 plies for core thickness $\mathrm{t} / 4, \mathrm{t} / 2,3 \mathrm{t} / 4$, respectively as given in Table 2 .

The comparison criteria include flexural stiffness, bending moment at the onset of failure and the ultimate bending moment the laminate can sustain. The flexural modulus of the laminate $\mathrm{E}_{\mathrm{f}}$ is calculated using the relation:

$$
\mathrm{E}_{\mathrm{f}}=\mathrm{M} \mid \kappa \mathrm{I}
$$

$\mathrm{I}=\mathrm{b}(2 \mathrm{t})^{3} / 12$ where, $\mathrm{b}$ is the width of the laminate which is a unit length. $\kappa$ is the curvature of the laminate at bending moment $\mathrm{M}$ according to Eq. 5 .

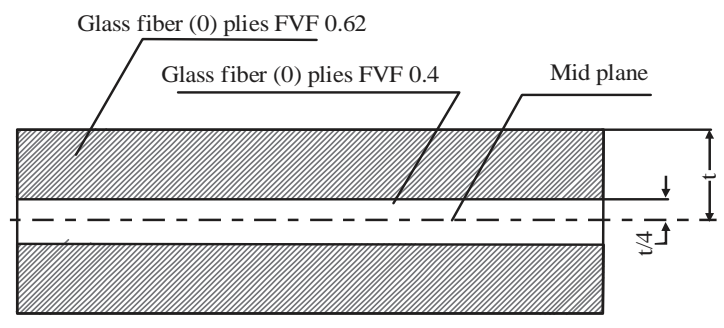

Fig. 3: $\left(0^{\circ}\right)$ laminate layup type II with core plies with thickness $\mathrm{t} / 4$ of FVF $40 \%$
The same procedure is followed to check the effect of hybrid volume fraction on the behaviour of off-axis laminates. The investigated laminate is 12 layers of glass fiber textile with layup $\left(0 / \pm 45^{\circ}\right)$ for each layer resulting in 36 plies symmetric laminate with total thickness $10.7 \mathrm{~mm}$. The thickness assigned for the $0^{\circ}$ plies is $0.443 \mathrm{~mm}$ and for the off-axis plies is $0.222 \mathrm{~mm}$. The fiber volume fraction of all plies is kept at $62 \%$ and analysed under bending moment in the global $\mathrm{X}_{1}$ direction. As for the case of $\left(0^{\circ}\right)$ laminates, the bending moment at onset of failure and at complete failure together with the flexural rigidity $\mathrm{E}_{\mathrm{f}}$ are recorded. This layup is given a designation of Type V. Then, two cases of hybrid volume fraction are investigated, designated Type VI and VII. For Type VI, a core of $t / 3$ is assigned to a lower volume fraction of $40 \%$. This thickness can be achieved by assigning this low volume fraction to 12 plies. A core of thickness $2 \mathrm{t} / 3$, which represents 24 plies, designated Type VII is assigned a low FVF of $40 \%$. The different hybridization is presented in Fig. 6 and 7.

The other loading case to be studied is tensile load. For the tensile loading, the relation between axial stress and axial strain for the mid plane, Eq. 4, is plotted for the

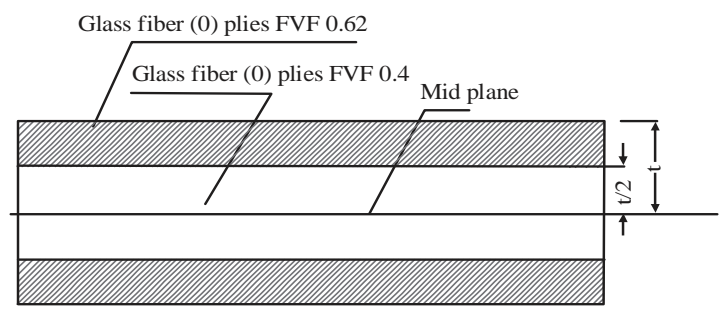

Fig. 4: $\left(0^{\circ}\right)$ laminate layup type III with core plies with thickness $\mathrm{t} / 2$ of FVF $40 \%$

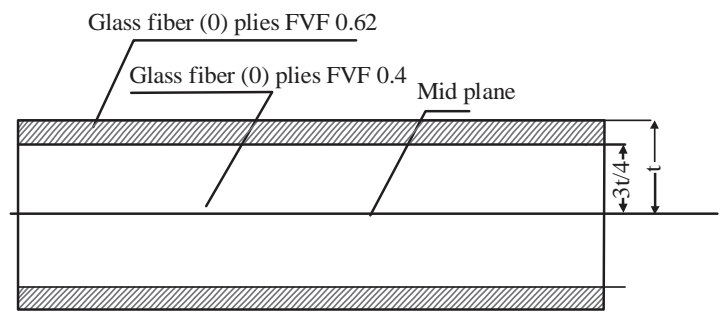

Fig. 5: $\left(0^{\circ}\right)$ laminate layup type IV with core plies with thickness $3 \mathrm{t} / 4$ of FVF $40 \%$

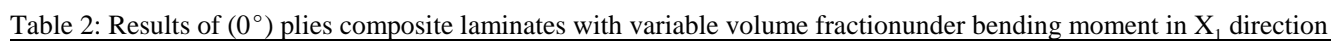

\begin{tabular}{|c|c|c|c|c|c|c|}
\hline Designation & $\begin{array}{r}\text { Reduced FVF core } \\
\text { thickness fraction }\end{array}$ & $\begin{array}{c}\text { Reduced FVF } \\
\text { core thickness (mm) }\end{array}$ & $\begin{array}{c}\text { Reduced FVF } \\
\text { core number of plies }\end{array}$ & $\begin{array}{c}\text { BM at onset of } \\
\text { failure }\left(\mathrm{kN} \mathrm{m} \mathrm{m}^{-1}\right)\end{array}$ & $\begin{array}{c}\text { BM at failure } \\
\left(\mathrm{kN} \mathrm{m} \mathrm{m}^{-1}\right)\end{array}$ & $\mathrm{E}_{\mathrm{f}}(\mathrm{GPa})$ \\
\hline Type I & 0 & 0.00 & 0 & 238 & 288 & 58.16 \\
\hline Type II & $\mathrm{t} / 4$ & 9.00 & 12 & 238 & 288 & 57.87 \\
\hline Type III & $t / 2$ & 18.0 & 24 & 225 & 275 & 56.05 \\
\hline Type IV & $3 t / 4$ & 27.0 & 36 & 225 & 250 & 51.06 \\
\hline
\end{tabular}


cases of hybrid FVF and compared with the laminate where all plies enjoy higher volume fraction of $62 \%$. The same two layups investigated under bending are utilised for axial loading.

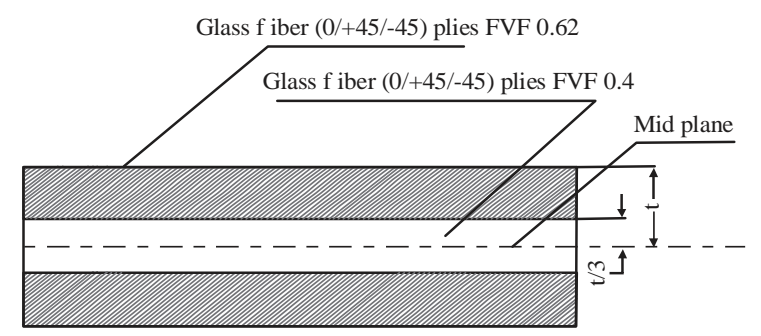

Fig. 6: $\left(0 / \pm 45^{\circ}\right)$ laminate layup type VI with core plies with thickness $\mathrm{t} / 3$ of FVF $40 \%$

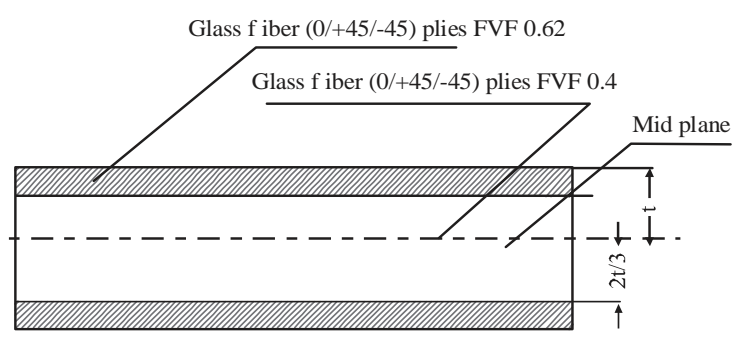

Fig. 7: $\left(0 / \pm 45^{\circ}\right)$ laminate type VII with core plies with thickness $2 \mathrm{t} / 3$ of FVF $40 \%$

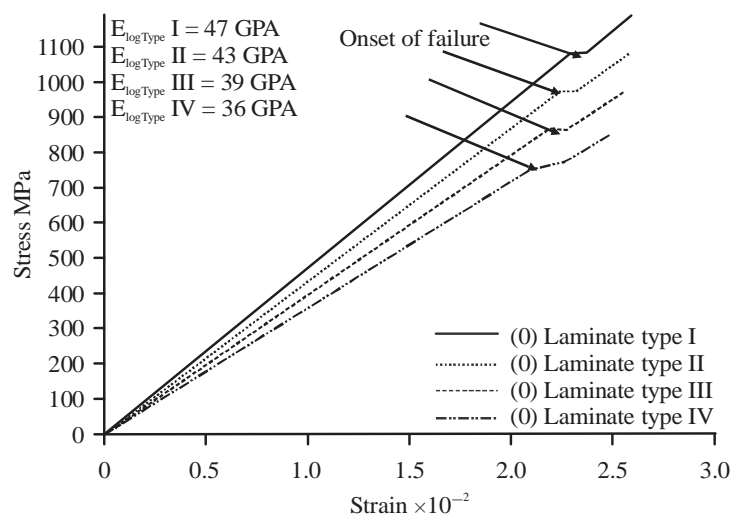

Fig. 8: Stress strain relationship for $\left(0^{\circ}\right)$ plies composite laminates with variable volume fraction under tension $\mathrm{X}_{1}$ direction

\section{RESULTS AND DISCUSSION}

The results of the $\left(0^{\circ}\right)$ laminate presented in the previous section under bending are shown in Table 2 . Comparing the results, it can be concluded that the effect of reduced core FVF on the mechanical behaviour of the axial laminates under bending is not significant. The reduction in any property ranges from $0 \%$ for narrow core to $12 \%$ for large core. The results of the $\left(0 / \pm 45^{\circ}\right)$ laminate are shown in Table 3 . The same phenomenon depicted in the $\left(0^{\circ}\right)$ is repeated here with slight reduction in any of the studied variables. For example, the reduction in the bending moment at the onset of failure may reach $18.2 \%$ when assigning low FVF for two thirds of the thickness.

For tensile load, the stress-strain relationship of the mid plane of the laminate for the $\left(0^{\circ}\right)$ and the $\left(0 / \pm 45^{\circ}\right)$ layups are given in Fig 8 and 9, respectively. From Fig. 8, it can be concluded that the reduction in the laminate stiffness due to the three hybridisation systems, when compared to Type I, is $8.5,15.8$ and $23.7 \%$. For the off-axis $\left(0 / \pm 45^{\circ}\right)$ laminate, Fig. 9 , the loss in the stiffness is $10 \%$ for $t / 3$ core thickness(Type VI) when compared with Type V. The reduction reaches $23 \%$ for $2 t / 3$ core thickness with volume fraction of $40 \%$ (Type VII).

Comparing the stress at the onset of failure for both layups,it is noticed that the onset of failure for Type I occurs at stress level of $1081 \mathrm{MPa}$ while for hybrid FVF

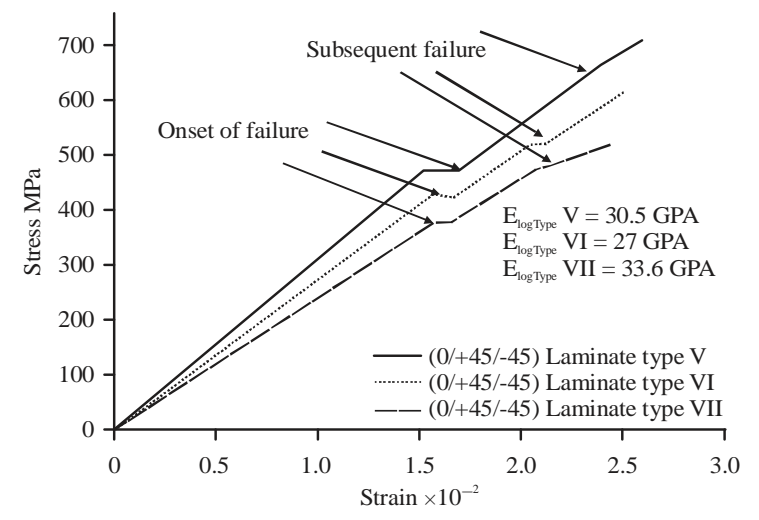

Fig. 9: Stress strain relationship for $0 / \pm 45^{\circ}$ plies composite laminates with variable volume fraction under tension in $\mathrm{X}_{1}$ direction

Table 3: Results of $\left(0 / \pm 45^{\circ}\right)$ plies composite laminates with variable volume fraction under bending moment in $\mathrm{X}_{1}$ direction

\begin{tabular}{lccccc}
\hline Designation & $\begin{array}{c}\text { Reduced FVF core } \\
\text { thickness fraction }\end{array}$ & $\begin{array}{c}\text { Reduced FVF } \\
\text { core thickness }(\mathrm{mm})\end{array}$ & $\begin{array}{c}\text { Reduced FVF } \\
\text { core number of plies }\end{array}$ & $\begin{array}{c}\text { BM at onset of } \\
\text { failure }\left(\mathrm{kN} \mathrm{m} \mathrm{m}^{-1}\right)\end{array}$ & $\begin{array}{c}\text { BM at failure } \\
\left(\mathrm{kN} \mathrm{m} \mathrm{m}^{-1}\right)\end{array}$ \\
\hline Type V & 0 & 0.00 & 0 & 11 & 16 \\
Type VI & $\mathrm{t} / 3$ & 3.55 & 12 & 10 & 32.4 \\
Type VII & $2 \mathrm{t} / 3$ & 7.10 & 24 & 9 & 15 \\
\hline
\end{tabular}


laminate Type II, III and IV occurs at 973, 865 and 757 MPa respectively. This represents 10, 20 and 30\% lower than the onset of failure stress of Type I. The same reduced percentages can be noticed for the failure stress for the three laminates. From Fig. 9 and for $\left(0 / \pm 45^{\circ}\right)$ laminate, the onset of failure occurs at stress 467,420 and 374 MPa for Type V, VI and VII. This represents 10\% and $20 \%$ reduction due to lower FVF in the core plies.For the failure stress, the reduced percentages attain higher values of $18.7,31 \%$. It is noticed that the loss in the onset of failure stress and the ultimate stress for such layup is more pronounced than the case of the $\left(0^{\circ}\right)$ layup due to the off-axis plies which give failure that is more tolerant.

It can be concluded from the results under bending and tension, that the behaviour of a hybrid FVF laminate, which contains some plies with reduced volume fraction, is much affected if it is subjected to tensile load rather than bending load. The results reveal that, under bending, the fiber volume fraction of the skin plies is what primarily controls the strength of the laminates especially for uniaxial laminates. This conclusion may be beneficial in the assessment of the reliability of some laminates that suffer suspicious in the fiber volume fraction due to manufacturing process. Such laminates behaviour can be enhanced by applying skin plies with higher fiber volume fraction which can be achieved using another manufacturing process. The overall behaviour in such a case is more reliable under the case of bending rather than tensile loads. It may be worthy to say that the effect of high stiffness skin layers can compensate the weak core plies especially for uniaxial laminates.

\section{CONCLUSION}

An investigation is presented on the behaviour of composite hybrid laminates in which some embedded plies suffer lower values of fiber volume fraction. The investigation includes laminates with different layups and with embedded core plies with different thicknesses that contain low values of fiber volume fraction. These laminates are investigated against bending moment and tensile load. It is concluded that the effect of low fiber volume fraction in some plies affects the tensile behavior in a more rigorous way than in bending. However, the effect goes to axial and flexural stiffness in addition to strength in bending and tensile loads.

\section{ACKNOWLEDGEMENT}

The researcher wishes to express her gratitude to the Center for Advanced Materials (CAM) at the British University in Egypt (BUE) for providing the experimental results conducted on various laminates for the purpose of verification of the model.

\section{REFERENCES}

ASTM., 2017. ASTM D3039/D3039M-17: Standard Test Method for Tensile Properties of Polymer Matrix Composite Materials. ASTM International, West Conshohocken, Pennsylvania, USA.

Bahei El-Din, Y.A., 2011. Sandwich structures for wind turbine blades. Report submitted to the European Commission, Brussels, Belgium.

Bahei-El-Din, Y.A. and A. Micheal, 2017. A multiscale model for damage progression and detection in piezo/pyroelectric composite laminates. Mech. Mater., 113: 77-88.

Bahei-El-Din, Y.A. and A.G. Botrous, 2003. Analysis of progressive fiber debonding in elastic laminates. Intl. J. Solids Struct., 40: 7035-7053.

Dvorak, G.J. and Y. Benveniste, 1992. On transformation strains and uniform fields in multiphase elastic media. Proc. Royal Soc., 437: 291-310.

Micheal, A.G. and Y.A. Bahei-El-Din, 2017. Detecting laminate damage using embedded electrically active plies-An analytical approach. Compos. Struct., 168: 772-779.

Mori, T. and K. Tanaka, 1973. Average stress in matrix and average elastic energy of materials with misfitting inclusions. Acta Metall., 21: 571-574.

Salgar Swapnil, A., B. Sathe Sandip, P. Chaudhari Bapu and S. JagadaleVishal, 2017. Experimental investigation of mechanical properties of glass fibre/epoxy composites with variable volume fraction. Mater. Today Proc., 4: 9487-9490.

Sureshkumar, P., B. Karthick, S. Dinakaran and R. Rajapradeepan, 2014. Experimental investigation of mechanical behavior of glass-fiber reinforced polyurethane resin composite in three different ratios. J. Eng. IOSRJEN., 6: 36-41. 